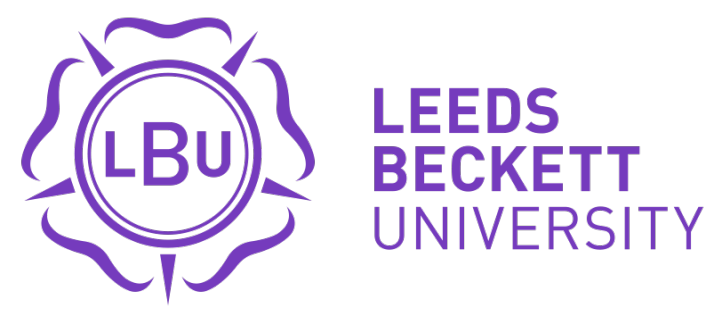

Citation:

Hendricks, S and Till, KA and Oliver, $\mathrm{J}$ and Johnston, $\mathrm{R}$ and Attwood, $\mathrm{M}$ and Brown, $\mathrm{J}$ and Drake, D and Macleod, S and Mellalieu, S and Jones, B (2018) Rating of Perceived Challenge as a measure of internal load for technical skill performance. British Journal of Sports Medicine, 53 (10). ISSN 1473-0480 DOI: https://doi.org/10.1136/bjsports-2018-099871

Link to Leeds Beckett Repository record:

https://eprints.leedsbeckett.ac.uk/id/eprint/5443/

Document Version:

Article (Accepted Version)

Creative Commons: Attribution-Noncommercial 4.0

The aim of the Leeds Beckett Repository is to provide open access to our research, as required by funder policies and permitted by publishers and copyright law.

The Leeds Beckett repository holds a wide range of publications, each of which has been checked for copyright and the relevant embargo period has been applied by the Research Services team.

We operate on a standard take-down policy. If you are the author or publisher of an output and you would like it removed from the repository, please contact us and we will investigate on a case-by-case basis.

Each thesis in the repository has been cleared where necessary by the author for third party copyright. If you would like a thesis to be removed from the repository or believe there is an issue with copyright, please contact us on openaccess@leedsbeckett.ac.uk and we will investigate on a case-by-case basis. 


\section{The Rating of Perceived Challenge as a measure of internal load for technical skill performance}

Sharief Hendricks ${ }^{1,2}$, Kevin Till ${ }^{2,3}$, Jon L Oliver ${ }^{4,5}$, Rich D Johnston ${ }^{6,7}$, Matthew Attwood ${ }^{4,8}$, James Brown ${ }^{9,13,1}$, David Drake ${ }^{10}$, Simon MacLeod ${ }^{10}$, Stephen D Mellalieu ${ }^{4}$, Ben Jones ${ }^{2,3,11,12}$

${ }^{1}$ Division of Exercise Science and Sports Medicine, University of Cape Town, Cape Town, South Africa ${ }^{2}$ Institute for Sport, Physical Activity and Leisure, Leeds Beckett University, Leeds, United Kingdom ${ }^{3}$ Yorkshire Carnegie Rugby Union Football Club, Leeds, United Kingdom

${ }^{4}$ School of Sport and Heath Sciences, Cardiff Metropolitan University, Cardiff, United Kingdom

${ }^{5}$ Sports Performance Research Institute New Zealand, Auckland University of Technology, Auckland, New Zealand

${ }^{6}$ School of Exercise Science, Australian Catholic University, Brisbane, Australia

${ }^{7}$ Norths Devils Rugby Football League, Queensland, Australia

${ }^{8}$ Cardiff Metropolitan University Rugby Union Football Club

${ }^{9}$ Institute for Sport and Exercise Medicine, Stellenbosch University, Stellenbosch, South Africa

${ }^{10}$ Ulster Rugby, Kingspan Stadium, Belfast, Northern Ireland

${ }^{11}$ The Rugby Football League, Leeds, United Kingdom

${ }^{12}$ The International Olympic Committee (IOC) Research Centre, Cape Town, South Africa ${ }^{14}$ Leeds Rhinos Rugby League Club, Leeds, United Kingdom

Correspondence to:

Sharief Hendricks, PhD

Division of Exercise Science and Sports Medicine, Department of Human Biology, Faculty of Health Sciences, the University of Cape Town and the Sports Science Institute of South

Africa, Cape Town, South Africa

PO Box 115

Newlands

7725

Tel: + 27-21-650-4572

Fax: +27-21-686-7530

sharief.hendricks01@gmail.com

Twitter: @Sharief_H

Keywords: Training Load, technical skill, injury prevention, rehabilitation, performance.

Word Count: 956

References: 11 


\section{Discussion}

Whether we are developing young athletes, designing injury prevention programmes, preparing high-level athletes for competition, or rehabilitating an athlete back to sport, the technical skill performance of the athlete(s) needs to be considered. Usually, technical skill performance is captured by training time (minutes), training frequency (number of sessions) or movement repetitions. ${ }^{1}$ However, this approach is limited by only assessing the external workload of the technical skill. Beyond the external workload, the athlete's physiological and psychological response to the load can also be assessed (termed internal load). ${ }^{1}$ One commonly used internal load measurement is the rating of perceived exertion (RPE) - a 0-10 or 0-100 category ratio rating scale where the lower end represents rest and the upper end maximal effort. Typically, the RPE scale is used to capture the athlete's global perceived experience of the physical work load. From a skill perspective however, this method provides little insight into the perceived technical demands of the movement(s). Weston and colleagues recognized this limitation and asked athletes to provide an RPE for the technical demand of matches and training (RPE-T). ${ }^{23}$ RPE scales however, are proposed as general intensity scales. ${ }^{4}$ This characteristic, arguably, can be considered as both an advantage (can be used for various applications) or a disadvantage if the instructions and anchors are not specific enough to the activity or event. Indeed, framing and wording of the instructions and anchors (and the intensities they represent) are important for the reliability and validity of a rating scale. ${ }^{5}$ Therefore, building on from the RPE-T, we present below the rating of perceived challenge (RPC) - an internal load measurement for technical skill underpinned by skill acquisition theory. This theoretical underpinning equips the RPC with technical skill specific instructions and anchors.

In a recent paper, we describe a technical skill training framework and skill load measurements for the rugby tackle. ${ }^{6}$ The paper was a follow-on from our British Journal of Sports Medicine paper, arguing for a planned contact-skill training programme to reduce the risk of tackle injuries while optimising performance within rugby. ${ }^{7}$ The technical skill training framework and skill load measurements were based on skill acquisition and skill development frameworks, including i) the constraints-based framework for skilled performance; $^{8}$ ii) the challenge point framework ${ }^{9}$ and iii) the skill acquisition periodization 
(SAP) framework. ${ }^{10}$ The technical skill training framework outlines the relationship between the difficulty of the task and the availability of information in the training environment. The relationship between the available information and the task difficulty provides the challenge point of the training session. ${ }^{6}$ Based on the technical ability of the athlete and the session objectives, the task difficulty and available information can be manipulated to set the optimal challenge point in order to maximise skill retention and transfer (skill learning).

\section{$* * *$ FIGURE 1 NEAR HERE***}

In the paper we propose that the challenge point be used as a measure to quantify skill load. ${ }^{9}{ }^{10}$ The challenge point describes the interaction between the difficulty of the task (dependent on the skill level of the player) and potential available information to the player (i.e., too much or too little information). ${ }^{9}$ The task difficulty (absolute and relative) and the available information is typically set by the coach and other practitioners (e.g., strength and conditioning coach, sport scientist, physiotherapist). For practical purposes, coaches and practitioners could use a visual analogue scale (VAS) from 1 to 10 (Figure 1) to rate the difficulty of the task and available information. For task difficulty, a rating of 1 on the VAS represents the execution of a set of coordinated movement patterns (technique), and 10, the proficient execution of the correct actions in response to the situation (skill proficiency) while fatigued (skill capacity). For the level of available information, a highly structured, lowrepresentative environment serves as the anchor for the lower extreme and a competitionlike environment serves as the upper extreme on the VAS (see Hendricks et al. 2018 for complete definitions). ${ }^{6}$ The resulting value from these two ratings represents the challenge point set by the coach or practitioner. In the context of technical skill training, the coach's or practitioner's challenge point can be considered an external subjective measure of technical skill load. To determine if the athlete experiences this challenge and works around the optimal challenge point, the athlete could be asked to rate how technically challenging they perceive the skill session to be (RPC), thus providing a measure of internal technical skill load (Figure 2). 
Assessing the internal and external technical load of a sport-specific movement has both clinical and performance applications. In a clinical setting for example, the RPC can help clinicians progress rehabilitating athletes from controlled movements and conditions (low $\mathrm{RPC}$ ) to more sport-specific movements and conditions (higher RPC), aiding the safe return to play decision-making process. ${ }^{11}$ From a performance perspective, the major application would be to monitor and plan technical skill training to prevent injury and illness, and optimize performance. The RPC is an internal load measurement for technical skill performance and therefore should be used in conjunction with other physical internal load measurements (for example, RPE) and external physical (for example, speed) and skill (for example, repetitions) to get a complete view of the workload of the activity.

In conclusion, using skill acquisition and skill development frameworks, we propose an approach to measuring the load of technical skill. How technically challenging a skill session was can be assessed through the rating of perceived challenge (RPC). Coaches and practitioners could easily add the RPC to their current data capturing systems to help monitor and prescribe skill training. Future research work in the area could focus on further validating the technical skill load measurements (or disprove its constructs) and determine its relationship to other physical load measurements and training modes, as well as potential links to injury, illness and performance.

\section{Acknowledgements}

The authors would like to thank the reviewers for their constructive and valuable input on the manuscript during the review process.

\section{Contributors}

SH drafted the first draft of the manuscript and all authors provided feedback and edits towards the final version. 


\section{References}

1. Soligard T, Schwellnus M, Alonso J-M, et al. How much is too much?(Part 1) International Olympic Committee consensus statement on load in sport and risk of injury. $\mathrm{Br} \mathrm{J}$ Sports Med 2016;50(17):1030-41.

2. Weston M, Siegler J, Bahnert A, et al. The application of differential ratings of perceived exertion to Australian Football League matches. J Sci Med Sport 2015;18(6):704-8. doi: 10.1016/j.jsams.2014.09.001

3. McLaren SJ, Smith A, Spears IR, et al. A detailed quantification of differential ratings of perceived exertion during team-sport training. J Sci Med Sport 2017;20(3):290-95.

4. Borg E, Love C. A demonstration of the Borg centiMax ${ }^{\circledR}$ Scale (CR100) for performance evaluation in diving. Nord Psychol 2017;1-17.

5. Borg G, Borg E. A new generation of scaling methods: Level-anchored ratio scaling. Psychologica 2001;28(1):15-45.

6. Hendricks S, Till K, Oliver JL, et al. A Technical Skill Training Framework and Skill Load Measurements for the Rugby Union Tackle. Strength \& Cond J 2018;40(5):44-59.

7. Hendricks S, Till K, Brown JC, et al. Rugby union needs a contact skill-training programme. Br J Sports Med 2017;51(10):829-30.

8. Davids KW, Button C, Bennett SJ. Dynamics of skill acquisition: A constraints-led approach: Human Kinetics 2008.

9. Guadagnoli MA, Lee TD. Challenge point: a framework for conceptualizing the effects of various practice conditions in motor learning. J Mot Behav 2004;36(2):212-24.

10. Farrow D, Robertson S. Development of a skill acquisition periodisation framework for high-performance sport. Sports Med 2017;47(6):1043-54.

11. Blanch P, Gabbett TJ. Has the athlete trained enough to return to play safely? The acute: chronic workload ratio permits clinicians to quantify a player's risk of subsequent injury. Br J Sports Med 2015:bjsports-2015-095445. 